\title{
Dust specific extinction cross-sections over the Eastern Mediterranean using the BSC-DREAM model and sun photometer data: the case of urban environments
}

\author{
E. Gerasopoulos ${ }^{1}$, P. Kokkalis ${ }^{2}$, V. Amiridis ${ }^{3}$, E. Liakakou ${ }^{1}$, C. Perez ${ }^{4}$, K. Haustein ${ }^{4}$, K. Eleftheratos ${ }^{5,6}$, \\ M. O. Andreae ${ }^{7}$, T. W. Andreae ${ }^{7}$, and C. S. Zerefos ${ }^{5,6}$ \\ ${ }^{1}$ Institute for Environmental Research and Sustainable Development, National Observatory of Athens, I. Metaxa \& V. Pavlou, \\ 15236, P. Penteli, Athens, Greece \\ ${ }^{2}$ National Technical University of Athens, Physics Department, Athens, Greece \\ ${ }^{3}$ Institute for Space Applications and Remote Sensing, National Observatory of Athens, I. Metaxa \& V. Pavlou, 15236, P. \\ Penteli, Athens, Greece \\ ${ }^{4}$ Earth Sciences Division, Barcelona Supercomputing Center, Barcelona, Spain \\ ${ }^{5}$ National Kapodistrian University of Athens, Geology Department, Athens, Greece \\ ${ }^{6}$ Biomedical Research Foundation, Academy of Athens, Athens, Greece \\ ${ }^{7}$ Biogeochemistry Department, Max Planck Institute for Chemistry, 55020 Mainz, Germany
}

Received: 31 March 2009 - Revised: 11 July 2009 - Accepted: 18 July 2009 - Published: 22 July 2009

\begin{abstract}
In this study, aerosol optical depth (AOD) measurements, from a MFR sun photometer operating in Athens, were compared with columnar dust loading estimations, from the BSC-DREAM model, during identified dust events, in order to extract the typical specific extinction crosssection for dust over the area. The selected urban environment of Athens provided us with the opportunity to investigate the mixing of dust and urban pollution and to estimate the contribution of the latter. The specific extinction cross-section for dust at $500 \mathrm{~nm}$ was found to be equal to $\sigma_{500}^{*}=0.64 \pm 0.04 \mathrm{~m}^{2} \mathrm{~g}$, typical for medium to large distances from dust sources, with weak wavelength dependence in the visible and near infrared band $(0.4-0.9 \mu \mathrm{m})$. The model showed a tendency to underpredict AOD levels for increasing values of the Ångström exponent, indicative of fine particles of anthropogenic origin inside the boundary layer. On average we found an AOD under-prediction of 10-15\% for Ångström exponents in the range of 0 to 1 and $30-40 \%$ in the range of 1 to 2 . Additionally, modelled surface concentrations were evaluated against surface $\mathrm{PM}_{10}$ measurements. Model values were lower than measured surface concentrations by $30 \%$ which, in conjunction with large scatter, in-
\end{abstract}

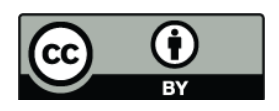

Correspondence to: E. Gerasopoulos (egera@meteo.noa.gr) dicated that the effect of the boundary layer anthropogenic contribution to columnar dust loadings is amplified near the ground.

Keywords. Atmospheric composition and structure (Aerosols and particles; Pollution - urban and regional; Instruments and techniques)

\section{Introduction}

Mineral dust mobilized over desert areas is injected into the atmosphere and travels large distances under favourable synoptic conditions. Dust particles modulate the Earth's radiation balance and thermal structure mainly via absorption and scattering of solar radiation, causing large uncertainties in the assessment of radiative forcing by aerosols (IPCC, 2007; Forster et al., 2007). Apart from impacts on climatic factors, dust also represents a high risk for human health due to particle inhalation (e.g., Yin et al., 2005) and for the air-transport sector due to reduced visibility (e.g., Seinfeld and Pandis, 1997; Malm and Day, 2000), especially in regions near the dust sources.

During the last decades, dust distribution and properties have been measured by many space- and ground-based techniques and also from aircrafts (e.g. Formenti et al., 2001a, b; Tanre et al., 2001; Diaz et al., 2001; Haywood et al., 2001;

Published by Copernicus Publications on behalf of the European Geosciences Union. 
Di Iorio et al., 2003; Kubilay et al., 2003). However, none alone is sufficient to fully describe the interrelations between its physical, chemical, and optical properties, and therefore the use of models has proven critical in integrating all the various measurements. Indeed, several regional models have been developed to simulate and predict, on an operational basis, the atmospheric dust cycle and processes (e.g., Nickovic and Dobricic, 1996; Kallos et al., 1997, Nickovic et al., 2001), as well as global models that simulate dust among major aerosol types (e.g. Chin et al., 2002; Tsigaridis et al., 2006).

However, before models can be used as operational predicting tools, they need to be evaluated using observations to increase confidence in their products and to reveal associated problems. Aerosol optical depth, being a standard and common product of satellite retrievals and ground-based remote sensing measurements, serves as a suitable variable to link models with observations. From the modeling point of view, the columnar burden of aerosols is given by the mass loading $M\left(\mathrm{~g} \mathrm{~m}^{-2}\right)$, or dust loading in the case of dust, which is related to aerosol optical depth (AOD) as follows (e.g. Lacis and Mishchenko, 1994):

$\mathrm{AOD}=\frac{3 Q M}{4 \rho r_{e}}$

where $Q$ is the extinction coefficient calculated from the Mie-scattering theory, $\rho$ is the particle density, and $r_{e}$ is the effective radius. Equation (1) simplifies to:

$\mathrm{AOD}=\sigma_{\lambda}^{*} M$

where $\sigma_{\lambda}^{*}$ is called "specific extinction cross-section" or "mass extinction efficiency" expressed in $\left(\mathrm{m}^{2} \mathrm{~g}^{-1}\right)$. In the case of dust, the dust loading $M$ is determined by source distribution and strength, as well as transport and removal processes and associated uncertainties. Equation (2) can be used to estimate the extinction cross-section for each type of aerosol via comparison between model-derived mass loadings and observations of AOD.

Extinction cross-sections are determined by the microphysical and optical properties of aerosols, namely, size distribution, refractive index and hygroscopic growth factor, which all depend strongly on the chemical composition of particles. In the case of dust, the composition is likely to change considerably from one location to another, resulting in significant changes in dust optical properties, which can range from highly absorbing to highly scattering (Sokolik and Toon, 1999). Apart from the identification and discrimination of dust source region, the extinction cross-sections for dust also depend on the distance from the source, i.e. coarser particles are more efficiently deposited than finer particles along their transport pathway (Formenti et al., 2001a). Finally, another significant difficulty arises from the treatment of aerosol mixing when more than one type of aerosol is present. All the above point out the need for estimating appropriate dust extinction cross-sections, from observationbased parameters used in models, which refer to different distances from dust sources and complicated aerosol mixing states.

In this study, we use AOD from ground-based measurements in Athens, Greece, to evaluate model derived predictions of dust transport over the region from neighbouring arid regions of North Africa and calculate appropriate extinction cross-sections for dust, from a number of selected dust cases. The urban environment of the megacity of Athens, in a loose definition of the term megacity, provides an excellent example for studying the contribution of Saharan dust aerosols to the overall aerosol burden of polluted Eastern Mediterranean cities, which have an already elevated background of both particulate and gaseous pollutants due to transport, local emissions, or photochemical production under high temperatures and insolation (e.g. Lelieveld et al., 2002; Kouvarakis et al., 2002; Gerasopoulos et al., 2005, 2006a). The availability of columnar and surface measurements of particulate matter gives us the opportunity to deduce model performance concerning both horizontal transport and vertical settlement of particles and optimise the calculation of extinction crosssection for dust over urban environments with strong mixtures of aerosol types (Fig. A1).

\section{Data and methods}

\subsection{BSC-DREAM model}

BSC-DREAM (Dust Regional Atmospheric Modeling) is a regional model designed to simulate all major processes of the atmospheric cycle of mineral dust aerosol by solving the Euler-type partial differential nonlinear equation for dust mass continuity (Nickovic et al., 2001). The configuration of the model used in this study includes four dust particle size classes (clay, small silt, large silt and sand) with particle size radii of $0.73,6.1,18$ and $38 \mu \mathrm{m}$, respectively. For the analysis of long-range transport, only the first two dust classes are relevant since their atmospheric life time is greater than about $12 \mathrm{~h}$ (see Perez et al., 2006, for details). The model products utilised here are the columnar dust loadings for the first two dust classes, the overall dust loading $\left(M_{1}, M_{2}\right.$ and $M$, respectively, in $\mathrm{g} \mathrm{m}^{-2}$ ) and the dust surface concentration $\left(C_{\text {surf }}, \mu \mathrm{g} \mathrm{m}^{-3}\right)$, evaluated every three hours. The model data comes from a 48-year simulation produced on the Marenostrum Supercomputer of the Barcelona Supercomputing Center (Pérez et al., 2007). In this model long run, meteorological fields were initialized every $24 \mathrm{~h}$ and boundary conditions updated every $6 \mathrm{~h}$ with the NCEP/NCAR I global reanalysis $(2.5 \times 2.5)$. The resolution used in this study is $0.3^{\circ} \times 0.3^{\circ}$ and 24 layers up to $15 \mathrm{~km}$ in the vertical. Model data are used for the time span 2005-2006 as far as it concerns analyses with AOD, and is extended to 2000-2006 when compared to surface $\mathrm{PM}_{10}$ concentrations. BSC-DREAM 
has been delivering operational dust $72 \mathrm{~h}$ forecasts over North Africa-Europe-Mediterranean (which include North of Africa, the Mediterranean basin, Middle East and Europe) and Asia regions in the last years (http://www.bsc.es/ projects/earthscience/DREAM). The model qualitative and quantitative verification studies performed so far (e.g. Balis et al., 2006; Pérez et al., 2006; Jiménez-Guerrero et al., 2008) using data from observation networks such as the European Lidar Network EARLINET, the AERONET/PHOTONS sun photometer network, satellite and ground-based PM levels (EMEP), outline the good skills of the model concerning both the horizontal and vertical extent of the dust plume in the geographic region of application. Additionally, the model has been validated and tested against measurements at source regions for SAMUM (Haustein et al., 2009) and BODEX campaigns (Todd et al., 2008).

\subsection{MFR data analysis}

In this study, we have used measurements of Aerosol Optical Depth (AOD) from a multi-filter rotating shadowband radiometer (MFR-7 Yankee Env. System Inc., Turner Falls, MA), located on the roof of the Research Center for Atmospheric Physics and Climatology of the Academy of Athens $\left(37^{\circ} 97^{\prime} \mathrm{N}, 23^{\circ} 79^{\prime} \mathrm{E}, 130 \mathrm{~m}\right.$ a.s.l.). The campus is located at a distance of about $6.5 \mathrm{~km}$ from the city centre and $10 \mathrm{~km}$ from the sea. The MFR provides 1-min average AODs at five wavelengths $(415,500,615,675$ and $867 \mathrm{~nm})$ and has been operated in the current location since November 2005. A description of the MFR operation principles can be found in Harrison et al. (1994), and the methodology for the retrieval of aerosol optical depth from measurements of the direct solar irradiance is described by Gerasopoulos et al. (2003). The instrument makes valid measurements during daytime and clear sky conditions and all necessary corrections are taken into account (Sun-Earth distance, contribution of Rayleigh scattering and ozone absorption from columnar ozone values taken from http://lap. physics.auth.gr/ozonemaps2/). The difficulty of discriminating cloud induced increases in optical depth (thin cirrus or more dense clouds) from abrupt changes in aerosol loadings, e.g. dust outbreaks, is overcome by utilizing maps of cloudiness and dust transport (http://www.bsc.es/projects/ earthscience/DREAM?cat_id=511, http://modis-atmos.gsfc. nasa.gov/IMAGES/index.html). Data from the MFR are averaged over a span of two hours centred on the model output time.

\subsection{Data selection criteria}

In urban environments, even under the intense and homogenous influence of dust transport (see Kalivitis et al., 2007, for Vertically Extended Transport (VET) cases), the contribution of mainly local, anthropogenic aerosol sources cannot be neglected. This limits the cases that are valid for the cal-

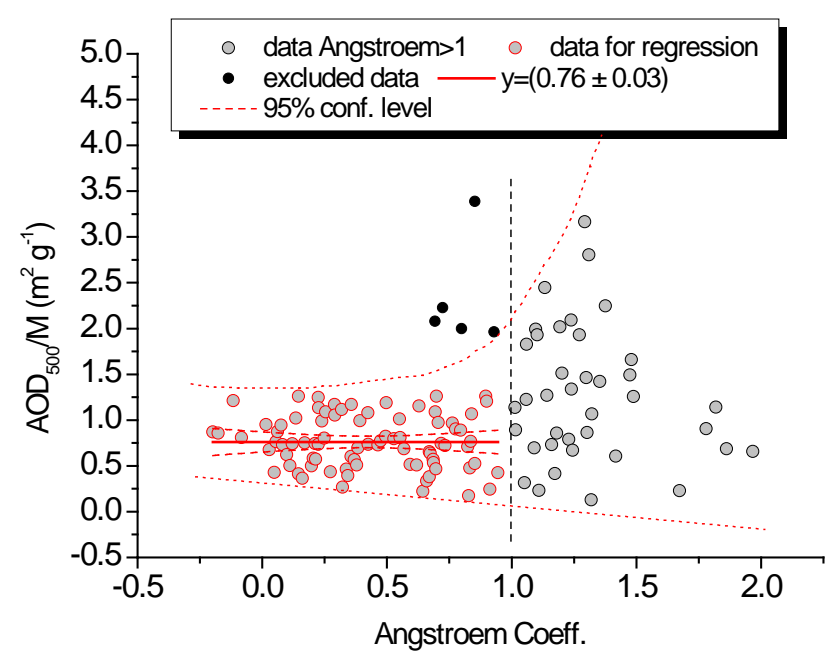

Fig. 1. The ratio of $\mathrm{AOD}$ at $500 \mathrm{~nm}$ from measurements by the MFR-7 radiometer in Athens to dust loading derived by the BSCDREAM model, as a function of the Angström exponent. The thick red line is the regression line for a fixed slope equal to 1 and for Ångström exponents lower than 1, and the dashed lines represent the standard error at the $95 \%$ confidence level. The dotted red lines illustrate in a free hand format the larger scatter for increasing Ångström exponents.

culation of dust extinction cross-sections at a certain distance from dust sources. To assure that the dust transport events are correctly identified we have set threshold values in both modelled dust loadings and the measured AOD. In particular, only dust loadings with $M>0.1 \mathrm{~g} \mathrm{~m}^{-2}$ were included in the analysis, a threshold corresponding to the $20 \%$ upper percentile, above which distinct peaks are observed in the complete time series (not shown here). As for AOD, background conditions at the area are encountered on a climatological basis during winter and range from $0.1-0.15$ (Gerasopoulos et al., 2003; Fotiadi et al., 2006). The time series of $\mathrm{AOD}_{500}$ over Athens, limited to the period used in this study, presents an average/median of $0.22 / 0.17$ and an upper quartile of 0.28 (unpublished data), in agreement with continental Mediterranean AOD levels reported in the past by Smirnov et al. (1995). Here we have selected a loose threshold of $\mathrm{AOD}_{500}>0.2$ as being representative of enhanced aerosol loadings, since a more strict discrimination of dust induced aerosol enhancement will be obtained via our third criterion, the Ångström exponent.

Fotiadi et al. (2006) and Kalivitis et al. (2007) associate the presence of dust particles over Crete Island, Greece, with Ångström exponents lower than 0.5-0.6. Perez et al. (2006) state that for Ångström exponent values larger than 0.6-0.8, the discrepancies between modelled and observed AOD are significant, as a clear sign of the fact that anthropogenic aerosols contribute significantly to the observed aerosol optical properties. For the case of Athens, we have plotted the ratio $\mathrm{AOD}_{500} / M$ versus the Ångström exponent, $\AA_{(415 / 867)}$, 


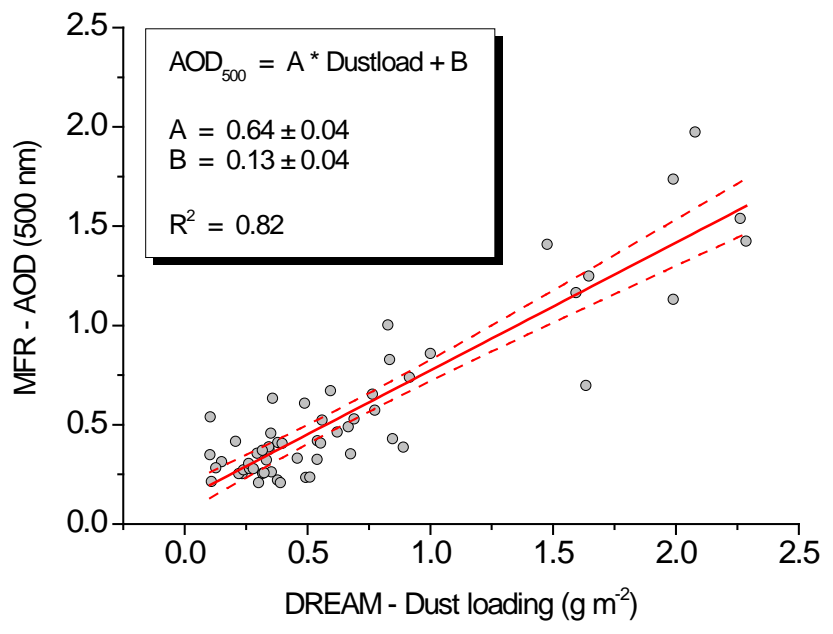

Fig. 2. AOD at $500 \mathrm{~nm}$ from MFR versus dust loading from the BSC-DREAM model, during selected dust cases that meet the criteria given in Sect. 2.3. The thick red line is the regression line and the dashed lines represent the standard error at the $95 \%$ confidence level.

to determine the Ångström exponent threshold values that can be used to eliminate periods with anthropogenic contamination, based on the physical characteristics of the particles (and in particular their size) (Fig. 1). This is necessary, because the ratio $\mathrm{AOD}_{500} / M$ only provides the dust extinction cross-section as long as the AOD is due to dust only, which is not generally the case in our study. In Fig. 1, a threshold of $\AA=1$ is revealed, with data points above this value presenting larger dispersion towards higher values of the $\mathrm{AOD}_{500} / M$ ratio, indicative of increasing influence from anthropogenic particles. For $\AA<1$, a fixed slope (=1) linear regression analysis provides an intercept of $0.76 \pm 0.03$, which would be the dust extinction cross-section at $500 \mathrm{~nm}$, including a bias from anthropogenic pollution or non-dust coarse particles in the area, e.g. sea salt.

Overall, for the current analysis and in order to select dust transport events from N. Africa for the calculation of dust extinction cross-sections, we have used the following combined criteria: dust loading, $M>0.1 \mathrm{~g} \mathrm{~m}^{-2}, \mathrm{AOD}_{500}>0.2$, and Ångström exponent, $\AA_{(415 / 867)}<1$.

\section{Results}

\subsection{Wavelength dependent dust extinction cross-sections, $\sigma_{\lambda}^{*}$}

From a 13-month period of overlapping measurements and model runs (November 2005-December 2006), 58 AOD $_{500}$ $\mathrm{M}$ pairs that meet the afore-mentioned criteria were selected, from about 15 distinct dust transport case studies (Fig. 2). The correlation between dust loading from the BSC-DREAM model and $\mathrm{AOD}_{500}$ from the MFR is signif-
Table 1. Results from linear regression analysis between AOD from the MFR at five wavelengths and dust loading from the BSCDREAM model, during dust events. The slope gives the extinction cross-section for dust and the intercept expresses the contribution of anthropogenic AOD.

\begin{tabular}{ccc}
\hline & \multicolumn{2}{c}{ Linear regression } \\
$\lambda(\mathrm{nm})$ & $\sigma_{\lambda}^{*} \pm$ std error & AOT $_{\text {anthr }} \pm$ std error \\
\hline 415 & $0.62 \pm 0.04$ & $0.19 \pm 0.04$ \\
500 & $0.64 \pm 0.04$ & $0.13 \pm 0.04$ \\
615 & $0.67 \pm 0.04$ & $0.10 \pm 0.04$ \\
671 & $0.67 \pm 0.04$ & $0.08 \pm 0.04$ \\
867 & $0.69 \pm 0.05$ & $0.06 \pm 0.04$ \\
\hline
\end{tabular}

icant at the $99 \%$ confidence level $\left(R^{2}=0.82\right)$, and the slope yields a dust extinction cross-section at $500 \mathrm{~nm}$ equal to $\sigma_{500}^{*}=0.64 \pm 0.04 \mathrm{~m}^{2} \mathrm{~g}$. The intercept of this regression expresses the contribution to the AOD at $500 \mathrm{~nm}$ of all other anthropogenic or natural, local or transported sources, which are not related to the dust transport predicted by the model. These could be fine anthropogenic particles from local urban sources or transported along medium to long distances from urban conglomerations and/or industrialized areas, but also coarse particles like sea salt or dust once more either locally resuspended or transported from neighbouring locations other than the dust source regions taken into account by the model. The chance of simultaneous transport from various sources over Greece, at different vertical layers, is discussed by Kalivitis et al. (2007). However in this study, we assume that the major excess contribution in the urban environment of Athens during dust events is from local anthropogenic particles. In this case, if the calculated intercept is added to $\sigma_{500}^{*}$, it agrees well with the biased extinction crosssection $(0.76$ at $500 \mathrm{~nm})$ found in Fig. 1. Similar calculations are repeated for the MFR's five wavelengths providing the respective extinction cross-sections (Table 1).

The extinction cross-section represents the optical depth or extinction coefficient for unit mass loading or mass concentration, respectively. In Fig. 3a we show the wavelength dependence of the retrieved dust extinction cross-sections. Applying the Ångström equation (Ångström, 1964) to the spectral distribution of $\sigma_{\lambda}^{*}$, we derive a negative Ångström exponent equal to $\AA=-0.15 \pm 0.02$, manifesting coarse particles. Typical values for coarse dust particles can be found below 0.5-0.6 (e.g. Eck et al., 1999; Fotiadi et al., 2006; Kalivitis et al., 2007) while negative values can be also encountered during dust storm conditions (e.g. Cachorro et al., 1989; Andreae et al., 2002; Xin et al., 2005),. The wavelength dependence of $\sigma_{\lambda}^{*}$, taking also into account the standard errors of their estimations, appears weak in the visible and near infrared band $(0.4-0.9 \mu \mathrm{m})$, in agreement with Mie theory for coarse particles and the observations of other authors (e.g., Holben et al., 2001; Andreae et al., 2002; Anderson et al., 2003; Formenti et al., 2000). 
When the same regression is applied to the intercepts of AOD versus dust loading (see Table 1), then typical urban conditions are obtained, dominated by fine particles $(\AA=1.69 \pm 0.04)$. The $\beta$ coefficients in these two plots correspond to the turbidity coefficient (in Fig. 3a, $\beta$ should be first multiplied by an average dust loading - in our selected cases the average dust loading is 0.7 thus giving a turbidity coefficient of 0.5) and they show a 3.5 times higher loading during the dust conditions. All the above demonstrate that our data selection criteria were adequate for the calculation of extinction cross-sections for dust, and that even though derived from data over an urban area, they are not significantly biased by anthropogenic pollution, and thus can be used for the estimation of AOD due to dust from columnar dust loadings.

Additionally, we have investigated whether the individual use of the first two dust classes instead of the overall dust loading, could serve as a better proxy for estimating AOD at different wavelengths. The correlations between $M_{1}, M_{2}$ and $M$ with $\operatorname{AOD}_{(\lambda)}$ has shown no significant difference (at the $95 \%$ confidence level). The only interesting feature is a maximum correlation for $\mathrm{AOD}_{500}$, contrary to the expected higher sensitivity to dust, or more correctly lower sensitivity to fine particles, for increasing wavelengths (Perez et al., 2006), however this cannot be statistically supported.

\subsection{Comparison between BSC-DREAM derived AODs and observations}

The extinction cross-sections for dust, calculated in this study, were used to compute the model derived AODs, which are compared here with the observed AODs. However, since the calculation of the extinction cross-sections is based on the same data set of observations, it should be pointed out that this comparison cannot serve as a complete and independent validation of the model. It is very useful, on the other hand, for evaluating the response of the model to different dust loadings during variable mixtures of aerosol types and can provide information on the mixing of dust and anthropogenic particles in urban environments.

First, we investigate whether the transformation from a modelled mass quantity to an optical property reproduces the basic features of the observed AOD over urban terrains. From the BSC-DREAM-estimated dust loadings we derive $\mathrm{AOD}_{500}$ values for the whole period. Then, only for the selected dust cases that meet the criteria of Sect. 2.3, we calculate their frequency distribution, which is directly compared with the respective frequency distribution from the MFR observations (Fig. 4). Model 2 refers to the calculation of $\mathrm{AOD}_{500}$ from the model taking also into account the intercept of the regression. The comparison shows that the main characteristics of the distribution are well reproduced, e.g. the class of maximum frequency and the existence of secondary peaks for $\mathrm{AOD}>1$. However, we see that while the observed distribution shows a cut-off threshold at 0.2 during
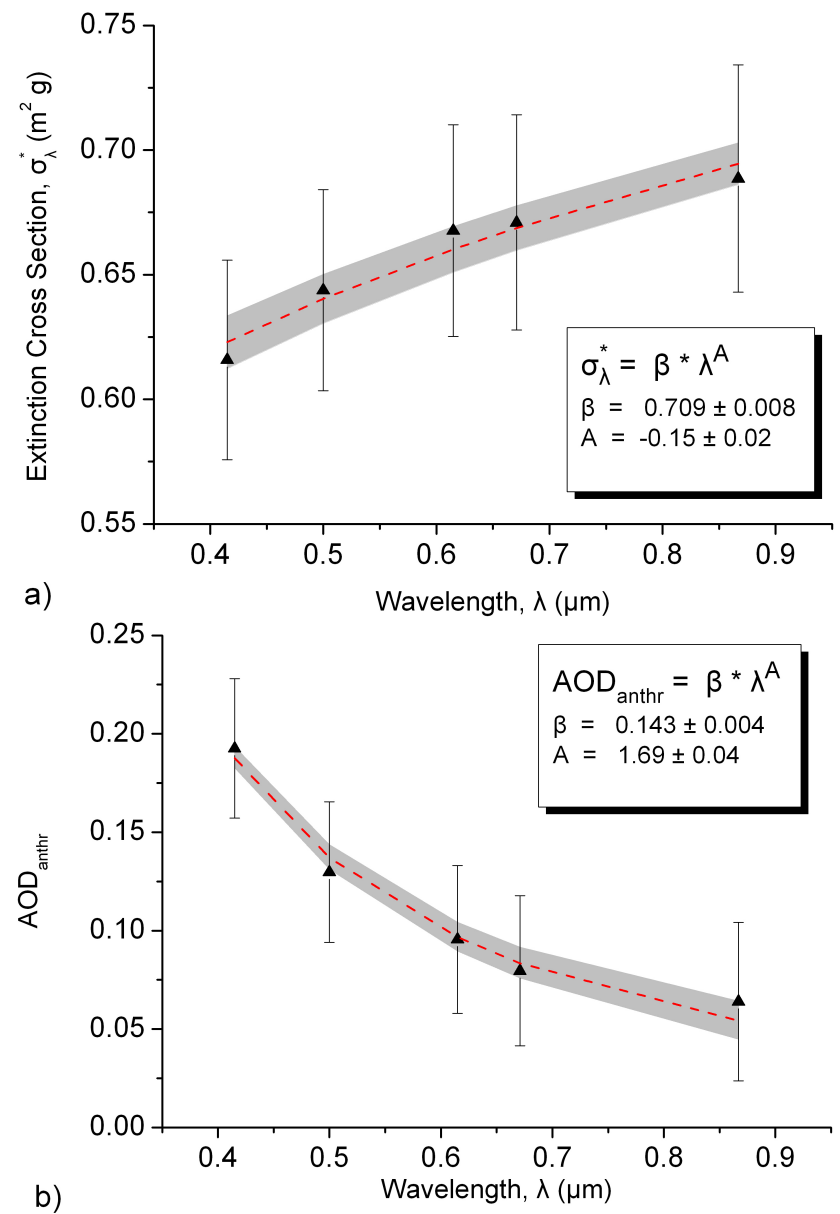

Fig. 3. Fitting of the Ångström equation on (a) the extinction crosssections calculated for different wavelengths as the slopes of regression analysis as in Fig. 2 and (b) the intercepts of the respective regression analysis for different wavelengths (values are taken from Table 1). The error bars correspond to the standard error of each point and the shaded area denotes the limits of the $95 \%$ confidence level of each fitting process.

the selected dust events (due to the respective selection criterion), modelled AODs also have values within the lowest bin (0-0.2). Moreover, the distribution of the modelled AOD presents lower skewness (1.4 instead of 1.7) than the distribution of observed AOD. Both possibly demonstrate the urban background influence which, however, cannot be resolved since it is not a simple linear shift. The latter is evidenced in Fig. 4 where the distribution for Model_2, which includes the influence of anthropogenic aerosols and nearby dust sources, is displaced to the right and does not actually agree with the observed distribution.

The model seems to underestimate AODs so far, most probably because it does not account for the influence of anthropogenic pollution. To qualitatively and quantitatively investigate the reasons for this underestimation we have plotted 


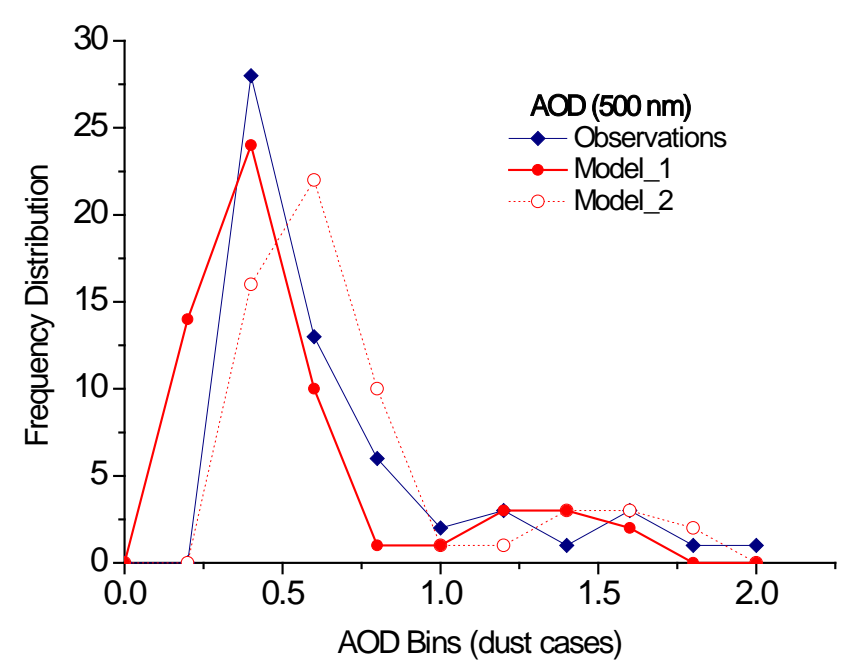

Fig. 4. Frequency distributions of observed AOD at $500 \mathrm{~nm}$ and modelled AODs calculated from BSC-DREAM dust loadings, applying the extinction cross-section value obtained from our analysis. Model_1 and Model_2 correspond to the non-inclusion and inclusion, respectively, of the calculated intercept that reflects anthropogenic and other local contributions.

the difference between modelled and observed $\mathrm{AOD}_{500}$ versus the Ångström exponent (Fig. 5). To bring out the role of urban pollution and estimate its contribution, we include in Fig. 5 all available data, without the constraint of the selection criteria that were used for the calculation of the dust extinction cross-sections, even though these data are still highlighted in the plot. Overall, $70 \%$ of the data lies in the model under-prediction area. Indeed, recent studies (Basart et al., 2009) confirm that AODs are generally underestimated by the model. Overestimation appears mainly in spring when strong precipitation events occur in the Mediterranean along the transport pathway of the dust plumes indicating the need for a more efficient wet scavenging scheme in the model. The regression line shows an increasing tendency of under-prediction by the model for higher Ångström exponents, which exactly demonstrates the aforementioned influence of fine particles from dominant local or nearby sources. Even during the better defined intense dust events (darker points) the under-prediction is still evidenced indicative of the persistent mixing of dust with urban particles inside the boundary layer, without of course disregarding cases of well structured elevated layers of dust. The rate of this under-prediction towards cases "contaminated" with anthropogenic particles is 0.07 AOD units per Ångström exponent unit, which gives on average an AOD under-prediction of 10$15 \%$ for Ångström exponents in the range of 0 to1 and 30$40 \%$ in the range of 1 to 2 .

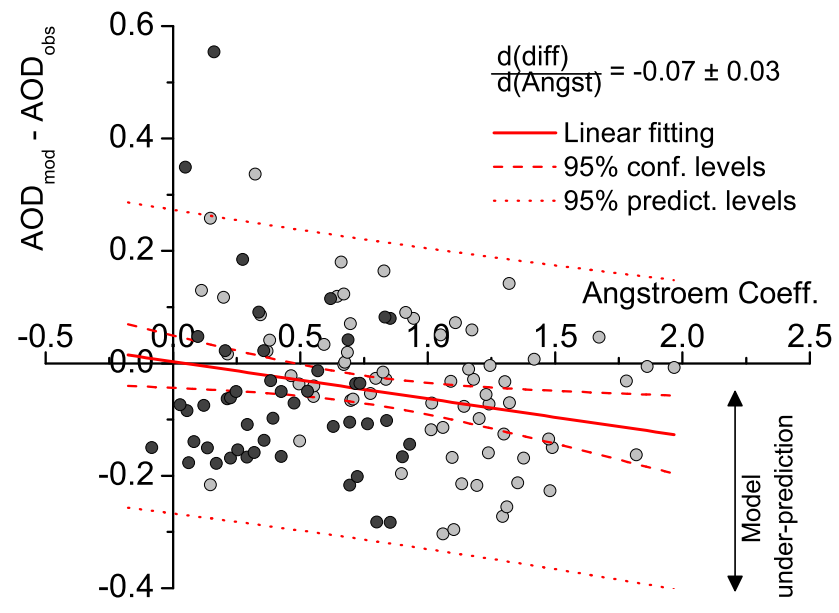

Fig. 5. The difference between modelled and observed AOD versus the Angström exponent. Darker points represent those data that meet the criteria of intense dust events (Sect. 2.3). The thick red line is the regression line, the dashed lines represent the standard error at the $95 \%$ confidence level, and the dotted lines correspond to the $95 \%$ prediction level.

\subsection{Estimation of surface $\mathbf{P M}_{10}$ concentrations}

One of the main goals of an operational dust transport prediction is the correct estimation of surface dust concentrations, because of its importance for human health. Especially in the Eastern Mediterranean, where PM levels can be extremely high (e.g. Querol et al., 2009a, b) the contribution of dust proves significant (e.g. Formenti et al., 2001b; Gerasopoulos et al., 2006b; Mitsakou et al., 2008). For this reason, we have compared the BSC-DREAM model estimates for dust surface concentrations with the $\mathrm{PM}_{10}$ data from the monitoring stations of the Ministry of Environment of Greece. From all stations we have selected the one which is closest to the location of the MFR instrument (Zografou station), to attain comparability of conditions with the AOD measurements also presented in this study. The specific station is characterised as suburban, and thus the influence of local pollution is reduced compared to stations located near the urban centre. Indeed, squared correlation coefficients, $R^{2}$, between daily $\mathrm{PM}_{10}$ at the Zografou station, and urban traffic influenced stations, are in the range $0.25-0.4$, while for other suburban or urban background stations the range rises to 0.550.75 , indicating relatively good representation of suburban conditions.

The analysis is based on daily-averaged values for the period of November 2000-December 2006 and is presented in Fig. 6. As expected, we observe large scatter in the values, and thus need to set some selection criteria, as in the case of AOD. In particular, it is evident that when the model predicts dust concentrations near the surface lower than $25 \mu \mathrm{g} \mathrm{m}^{-3}$, there is no sign of correlation with observations due to the proportionally high influence of local 
contributions. Excluding these cases, there remains 35\% that correspond to cases where even though the model presents significant dust loadings near the surface, it is not reflected in the observations (we used a subjective criterion of $10 \mu \mathrm{g} \mathrm{m}^{-3}$ difference between model and observations). For the rest of the cases, we calculated a regression line (intercept forced to zero) and the resulting slope (1.4 \pm 0.1$)$ once more demonstrates the still high influence of local sources to the levels of $\mathrm{PM}_{10}$, even during dust events.

\section{Conclusions and discussion}

In the current work we utilised aerosol optical depth (AOD) measurements from a MFR radiometer operating in Athens and dust loading from the BSC-DREAM model during identified dust events, in order to extract typical specific extinction cross-sections for dust over the area. The model-derived AOD was compared to the observations, giving information about the mixing of dust with anthropogenic particles at urban environments. This statistical approach gives results that correspond to the typical chemical composition of dust prevailing at our site, and average distances of our site from dust sources.

We retrieved an extinction cross-section for dust at $500 \mathrm{~nm}$ equal to $\sigma_{500}^{*}=0.64 \pm 0.04 \mathrm{~m}^{2} \mathrm{~g}^{-1}$. Extinction cross-sections were also calculated for additional wavelengths and the wavelength dependence of $\sigma_{\lambda}^{*}$ was found to be weak in the visible and near infrared band $(0.4-0.9 \mu \mathrm{m})$. The value of $\sigma_{500}^{*}$ from this study lies well within the range of values given for large distances from sources. In particular, Moulin et al. (1997) and Perez et al. (2006), in reviewing several extinction cross-sections from dust models report $\sigma_{550}^{*}$ in the range of 0.12-0.23 near dust sources (e.g. Koepke and Hess, 1988; D'Almeida, 1987) and 0.4-0.8 at larger distances from the source (e.g. Koepke and Hess, 1988; D'Almeida, 1987; Dulac et al., 1992; Perez et al., 2006). Average distances of Athens from typical dust sources in Northern Africa (e.g. Engelstaedter and Washington, 2007) are in the range 1000$3000 \mathrm{~km}$.

While there are not many studies retrieving extinction cross-sections for the area, mass scattering cross-sections (or efficiencies) for dust of 0.21 and $0.96 \mathrm{~m}^{2} \mathrm{~g}^{-1}$ have been reported for two sites in the Eastern Mediterranean by Vrekoussis et al. (2005). These values reflect the effect only of scattering, not total, extinction as in this study, but the authors show that scattering contributes about $90 \%$ of the extinction in the area. Andreae et al. (2002) estimate mass scattering cross-sections for dust in the Negev desert, Israel, at $0.52 \mathrm{~m}^{2} \mathrm{~g}^{-1}\left(0.71 \mathrm{~m}^{2} \mathrm{~g}^{-1}\right.$ after correction for nonLambertian behaviour and truncation errors of the nephelometer) and provide a detailed review of mass scattering cross-sections for different types of aerosols (their Table 5). Scattering cross-sections for coarse particles are also given from measurements at desert areas in the United States.

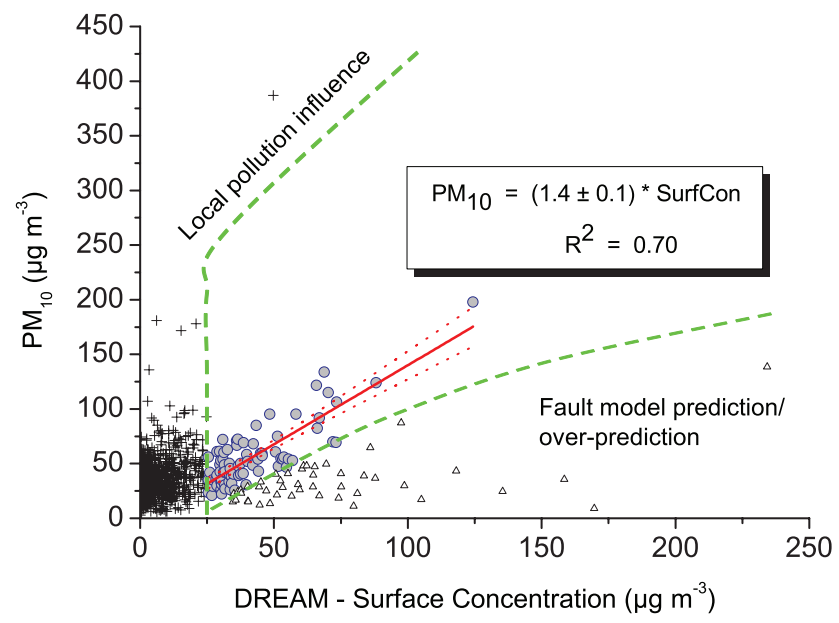

Fig. 6. $\mathrm{PM}_{10}$ measured at a ground station in Athens versus the surface concentration of dust particles derived from the BSC-DREAM model. Crosses and triangles are cases of high local pollution influence and are not confirmed by observations or model predicted dust events, respectively. Circles correspond to the cases taken into account for the regression analysis.

Malm and Day (2000, and references therein) have retrieved values in the range of $0.4-0.6 \mathrm{~m}^{2} \mathrm{~g}^{-1}$ (the contribution of dust being as much as $50 \%$ ), reporting a weak inverse relationship between scattering cross-sections and coarse mass concentration.

Having estimated the extinction cross-section for dust over our study area, AOD values were next extracted from the model. In general, the model demonstrated a tendency to underpredict AOD for increasing values of the Ångström exponent (on average we find an AOD under-prediction of 10$15 \%$ for Ångström exponents in the range of 0 to 1 and 30$40 \%$ in the range of 1 to 2), confirming previous findings (e.g. Perez et al., 2006) that propose the influence of anthropogenic pollution inside the boundary layer as one of the reasons for the underprediction. Apart from the underprediction of AOD values towards finer particles, the characteristics of the AOD frequency distribution are relatively well reproduced, however the effects of local pollution produces some slight differences in cut-off thresholds and skewness of the distributions that cannot be easily interpreted, since effects are case-wise with no linear behaviour.

The attempt to evaluate model surface concentrations from surface $\mathrm{PM}_{10}$ measurements proved to be more difficult. Large scatter of the values lead us to a number of assumptions in order to derive the regression line between modelled and measured surface concentrations. The finding was that BSC-DREAM surface concentrations are lower by $30 \%$. This percentage expresses the average contribution of urban particles to surface concentrations when dust presence is predicted over Athens by the model. The failure in representing surface concentrations at urban environments is expected 
since the effect of the boundary layer anthropogenic contribution to dust loadings is amplified near ground.

Apart from the impact of boundary layer pollution, other parameters are crucial for the correct estimation of dust loading and thus AODs over an area. These include, among others, the treatment of source terms to adequately simulate the production phase of the dust cycle and the fact that, since sunphotometric observations are point measurements, they may not always be representative of the larger gridbox of a model.

\section{Appendix A}

\section{Example of Saharan dust and local air pollution mixture over Athens, Greece}

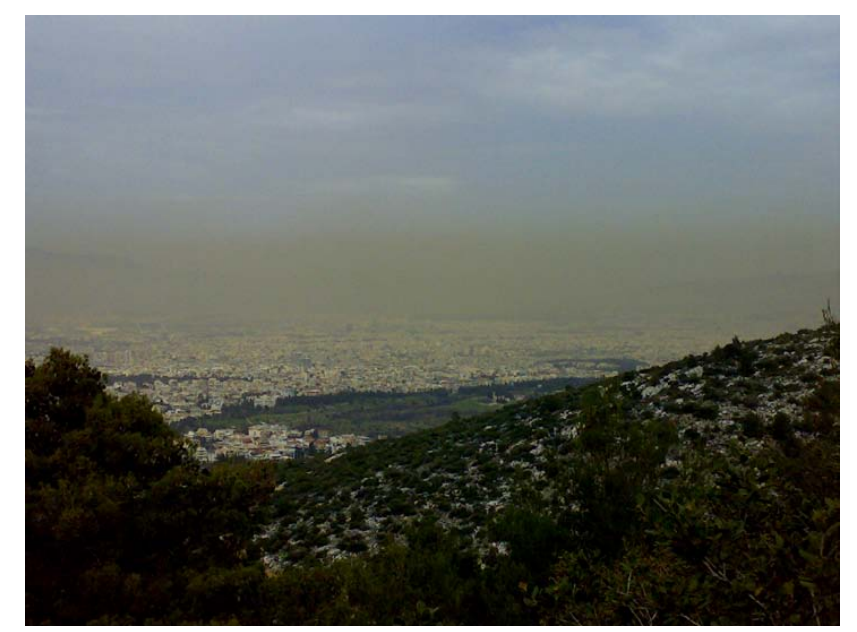

Fig. A1. Mixture of Saharan dust aerosols and local air pollution over Athens, Greece. Photo taken on 31 March 2009.

Acknowledgements. We would like to acknowledge support by the NASA Grant: NNX06AF30G - Global Environmental Changehazards and regional impacts, and support by the technical officers Don Anderson and Lucia Tsaoussi. The support of the Academy of Athens which hosts the MFR radiometer is greatly acknowledged. Part of this work was performed within the EU-FP6 project CIRCE.

Topical Editor F. D'Andrea thanks three anonymous referees for their help in evaluating this paper.

\section{References}

Anderson, T. L., Masonis, S. J., Covert, D. S., Ahlquist, N. C., Howell, S. G., Clarke, A. D., and McNaughton, C. S.: Variability of aerosol optical properties derived from in situ aircraft measurements during ACE-Asia, J. Geophys. Res., 108, 8647, doi:10.1029/2002JD003247, 2003.

Andreae, T. W., Andreae, M. O., Ichoku, C., Maenhaut, W., Cafmeyer, J., Karnieli, A., and Orlovsky, L.: Light scattering by dust and anthropogenic aerosol at a remote site in the Negev desert, Israel, J. Geophys. Res., 107, 4008, doi:10.1029/2001JD900252, 2002.

Ångström, A.: The parameters of atmospheric turbidity, Tellus XIVV, 14, 64-75, 1964.

Balis, D., Amiridis, V., Kazadzis, S., Papayannis, A., Tsaknakis, G., Tzortzakis, S., Kalivitis, N., Vrekoussis, M., Kanakidou, M., Mihalopoulos, N., Chourdakis, G., Nickovic, S., Pérez, C., Baldasano, J., and Drakakis, M.: Optical characteristics of desert dust over the East Mediterranean during summer: a case study, Ann. Geophys., 24, 807-821, 2006, http://www.ann-geophys.net/24/807/2006/.

Basart, S., Pérez, C., Cuevas, E., and Baldasano, J. M.: Evaluation of a regional mineral dust model over Northern Africa, Southern Europe and Middle East with AERONET data, European Geosciences Union., 19-24 April 2009, Vienna, Austria, 2009.

Cachorro, V. E., Gonzalez, M. J., de Frutos, A. M., and Casanova, J. L.: Fitting Ångström's formula to spectrally resolved aerosol optical thickness, Atmos. Environ., 23(1), 265-270, 1989.

Chin, M., Ginoux, P., Kinne, S., Torres, O., Holben, B. N., Duncan, B. N., Martin, R. V., Logan, J. A., Higurashi, A., and Nakajima, T.: Tropospheric aerosol optical thickness from the GOCART model and comparisons with satellite and Sun photometer measurements, J. Atmos. Sci., 59, 461-483, 2002.

D'Almeida, D. A.: On the variability of desert aerosol radiative characteristics, J. Geophys. Res., 92, 3017-3026, 1987.

Diaz, J. P., Exposito, F. J., Torres, C. J., Herrera, F., Prospero, J. M., and Romero, M. C.: Radiative properties of aerosols in Saharan dust outbreaks using ground-based and satellite data: Applications to radiative forcing, J. Geophys. Res., 106, 18403-18416, 2001.

Di Iorio, T., di Sarra, A., Junkermann, W., Cacciani, M., Fiocco, G., and Fua, D.: Tropospheric aerosols in the Mediterranean: 1. Microphysical and optical properties, J. Geophys. Res., 108, 4316, doi:10.1029/2002JD002815, 2003.

Dulac, F., Tanri, D., Bergametti, G., Buat-Minard, P., Desbois, M., and Sutton, D.: Assessment of the African airborne dust mass over the western Mediterranean Sea using Meteosat data, J. Geophys. Res., 97, 2489-2560, 1992.

Eck, T. F., Holben, B. N., Reid, J. S., Dubovik, O., Smirnov, A., O'Neill, N. T., Slutsker, I., and Kinne, S.: Wavelength dependence of the optical depth of biomass burning, urban, and desert dust aerosols, J. Geophys. Res., 104(D24), 31333-31349, 1999.

Engelstaedter, S. and Washington, R.: Atmospheric controls on the annual cycle of North African dust, J. Geophys. Res., 112, D03103, doi:10.1029/2006JD007195, 2007.

Formenti, P., Andreae, M. O., and Lelieveld, J.: Measurements of aerosol optical depth above $3570 \mathrm{~m}$ asl in the North Atlantic free troposphere: Results from ACE-2, Tellus, 52B, 678-693, 2000.

Formenti, P., Andreae, M. O., Lange, L., Roberts, G., Cafmeyer, J., Rajta, I., Maenhaut, W., Holben, B. N., Artaxo, P., and Lelieveld, J.: Saharan dust in Brazil and Suriname during the Large-Scale Biosphere-Atmosphere Experiment in Amazonia (LBA) - Cooperative LBA Regional Experiment (CLAIRE) in March 1998, J. Geophys. Res., 106, 14919-14934, 2001a.

Formenti, P., Andreae, M. O., Andreae, T. W., Galani, E., Vasaras, A., Zerefos, C., Amiridis, V., Orlovsky, L., Karnieli, A., Wendisch, M., Wex, H., Holben, B. N., Maenhaut, W., and Lelieveld, J.: Aerosol optical properties and large-scale transport of air masses: Experimental observations from a coastal and a 
semi-arid site in the Eastern Mediterranean during summer 1998, J. Geophys. Res., 106, 9807-9826, 2001 b.

Forster, P., Ramaswamy, V., Artaxo, P., Berntsen, T., Betts, R., Fahey, D. W., Haywood, J., Lean, J., Lowe, D. C., Myhre, G., Nganga, J., Prinn, R., Raga, G., Schulz, M., and Van Dorland, R.: Changes in Atmospheric Constituents and in Radiative Forcing, in: Climate Change 2007: The Physical Science Basis. Contribution of Working Group I to the Fourth Assessment Report of the Intergovernmental Panel on Climate Change, edited by: Solomon, S., Qin, D., Manning, M., Chen, Z., Marquis, M., Averyt, K. B., Tignor, M., and Miller, H. L., Cambridge University Press, Cambridge, United Kingdom and New York, NY, USA, 2007.

Fotiadi, A., Hatzianastassiou, N., Drakakis, E., Matsoukas, C., Pavlakis, K. G., Hatzidimitriou, D., Gerasopoulos, E., Mihalopoulos, N., and Vardavas, I.: Aerosol physical and optical properties in the Eastern Mediterranean Basin, Crete, from Aerosol Robotic Network data, Atmos. Chem. Phys., 6, 53995413, 2006, http://www.atmos-chem-phys.net/6/5399/2006/.

Gerasopoulos, E., Andreae, M. O., Zerefos, C. S., Andreae, T. W., Balis, D., Formenti, P., Merlet, P., Amiridis, V., and Papastefanou, C.: Climatological aspects of aerosol optical properties in Northern Greece, Atmos. Chem. Phys., 3, 2025-2041, 2003, http://www.atmos-chem-phys.net/3/2025/2003/.

Gerasopoulos, E., Kouvarakis, G., Vrekoussis, M., Kanakidou, M., and Mihalopoulos, N.: Ozone variability in the marine boundary layer of the Eastern Mediterranean based on 7-year observations. J. Geophys. Res., 110, D15309, doi:10.1029/2005JD005991, 2005.

Gerasopoulos, E., Kouvarakis, G., Vrekoussis, M., Donoussis, C., Mihalopoulos, N., and Kanakidou, M.: Photochemical ozone production in the Eastern Mediterranean, Atmos. Environ., 40, 3057-3069, 2006a.

Gerasopoulos, E., Kouvarakis, G., Babasakalis, P., Vrekoussis, M., Putaud, J. P., and Mihalopoulos, N.: Origin and variability of particulate matter $\left(\mathrm{PM}_{10}\right)$ mass concentrations over the Eastern Mediterranean, Atmos. Environ., 40, 4679-4690, $2006 \mathrm{~b}$.

Harrison, L., Michalsky, J., and Berndt, J.: Automated multifilter rotating shadow-band radiometer: an instrument for optical depth and radiation measurements, Appl. Optics, 33, 5118-5125, 1994.

Haustein, K., Pérez, C., Baldasano, J. M., et al.: Regional dust model performance during SAMUM 2006. Geoph. Res. Lett., 36, L03812, doi:10.1029/2008GL036463, 2009.

Haywood, J. M., Francis, P. N., Glew, M. D., and Taylor, J. P.: Optical properties and direct radiative effect of Saharan dust: A case study of two Saharan dust outbreaks using aircraft data, J. Geophys. Res., 106, 18417-18430, 2001.

Holben, B. N., Tanre, D., Smirnov, A., et al.: An emerging ground-based aerosol climatology: Aerosol optical depth from AERONET, J. Geophys. Res., 106, 12067-12097, 2001.

IPCC, Climate Change 2007: The Physical Science Basis. Contribution of Working Group I to the Fourth Assessment Report of the Intergovernmental Panel on Climate Change, edited by: Solomon, S., Qin, D., Manning, M., Chen, Z., Marquis, M., Averyt, K. B., Tignor, M., and Miller, H. L., Cambridge University Press, Cambridge, United Kingdom and New York, NY, USA, 996 pp, 2007.

Jiménez-Guerrero, P., Pérez, C., Jorba, O., and Baldasano, J. M.:
Contribution of Saharan dust in an integrated air quality system and its on-line assessment, Geophys. Res. Lett., 35(3), L03814, doi:10.1029/2007GL031580, 2008.

Kalivitis, N., Gerasopoulos, E., Vrekoussis, M., Kouvarakis, J., Kubilay, N.: Dust transport over the eastern Mediterranean derived from total Ozone Mapping Spectrometer, Aerosol Robotic Network, and surface measurements, J. Geophys. Res., 112, D03202, doi:10.1029/2006JD007510, 2007.

Kallos, G., Nickovic, S., Papadopoulos, A., Jovic, D., Kakaliagou, O., Misirlis, N., Boukas, L., Mimikou, N., Sakellaridis, G., Papageorgiou, J., Anadranistakis, E., and Manousakis, M.: The regional weather forecasting system SKIRON: An overview, International Symposium on Regional Weather Prediction on Paralle Computer Environments, Athens, Greece, 15-17 October 1997.

Koepke, P. and Hess, M.: Scattering functions of tropospheric aerosols: The effect of nonspherical particles, Appl. Optics, 27, 2422-2430, 1988.

Kouvarakis, G., Vrekoussis, M., Mihalopoulos, N., Kourtidis, K., Rappenglueck, B., Gerasopoulos, E., and Zerefos, C.: Spatial and temporal variability of tropospheric ozone (O3) in the boundary layer above the Aegean Sea (eastern Mediterranean), J. Geophys. Res., 107(D18), 8137, doi:10.1029/2000JD000081, 2002.

Kubilay, N., Cokacar, T., and Oguz, T.: Optical properties of mineral dust outbreaks over the northeastern Mediterranean, J. Geophys. Res., 108(D21), 4666, doi:10.1029/2003JD003798, 2003.

Lacis, A. A. and Mishchenko, M. I.: Climate forcing, climate sensitivity, and climate response: A radiative modeling perspective on atmospheric aerosols. Aerosol Forcing of Climate, edited by: Charlson, R. J. and Heintzenberg, J., John Wiley and Sons, 416 pp, 1994.

Lelieveld, J., Berresheim, H., Borrmann, S., et al.: Global air pollution crossroads over the Mediterranean, Science, 298, 794-799, 2002.

Malm, W. C. and Day, D. E.: Optical properties of aerosols at Grand Canyon National Park, Atmos. Environ., 34, 3373-3391, 2000.

Mitsakou, C., Kallos, G., Papantoniou, N., Spyrou, C., Solomos, S., Astitha, M., and Housiadas, C.: Saharan dust levels in Greece and received inhalation doses, Atmos. Chem. Phys., 8, 71817192, 2008, http://www.atmos-chem-phys.net/8/7181/2008/.

Moulin, C., Dulac, F., Lambert, C. E., Chazette, P., Jankowiak, I., Chatenet, B., and Lavenu, F.: Long term daily monitoring of Sharan dust load over ocean using Meteosat ISCCP-B2 data: 2. Accuracy of the data and validation using sunphotometer measurements, J. Geophys. Res., 102, 16959-19969, 1997.

Nickovic, S. and Dobricic, S.: A Model for Long-Range Transport of Desert Dust, Mon. Weather Rev., 124(11), 2537-2544, 1996.

Nickovic, S., Papadopoulos, A., Kakaliagou, O., and Kallos, G.: Model for prediction of desert dust cycle in the atmosphere, J. Geophys. Res., 106, 18113-18129, 2001.

Pérez, C., Nickovic, S., Baldasano, J. M., Sicard, M., Rocadenbosch, F., and Cachorro, V. E.: A long Saharan dust event over the western Mediterranean: Lidar, Sun photometer observations, and regional dust modeling, J. Geophys. Res., 111, D15214, doi:10.1029/2005JD006579, 2006.

Pérez, C., Jiménez-Guerrero, P., Jorba, O., Baldasano, J. M., Cuevas, E., Nickovic, S., and Querol, X.: Long-term simulations (1958-2006) of Saharan dust over the Mediterranean and the Eastern North Atlantic with the DREAM regional dust model. In: XXIV International Union of Geodesy and Geophysics (IUGG) 
General Assembly, Perugia, Italy, 2-13 July 2007.

Querol, X., Pndolfi, M., Pey, J., Alastuey, A., Cusack, M., Pérez, M., Amato, F., Moreno, T., Viana, M., and Mihalopoulos, N.: African dust contribution to mean ambient $\mathrm{PM}_{10}$ across the Mediterranean Basin: A quantitative approach to investigate spatial and seasonal patterns, Geophys. Res. Abstracts, 11, 8724, 2009a.

Querol, X., Alastuey, A., Pey, J., Cusack, M., Prez, N., Mihalopoulos, N., Theodosi, C., Gerasopoulos, E., Kubilay, N., and Koçak, M.: Variability in regional background aerosols within the Mediterranean, Atmos. Chem. Phys., 9, 4575-4591, 2009b, http://www.atmos-chem-phys.net/9/4575/2009/.

Seinfeld, J. and Pandis, S.: Atmospheric Chemistry and Physics: From Air Pollution to Climate Changes, ch. 22 Radiative effects of atmospheric aerosols: visibility and climate, p. 1113, John Wiley, Hoboken, N. J., 1997.

Smirnov, A., Villevalde, Y., O’Neill, N. T., Royer, A., and Tarusso, A.: Aerosol optical depth over the oceans: Analysis in terms of synoptic air mass types, J. Geopsy. Res., 100(D8), 16639-16650, 1995.

Sokolik, I. N. and Toon, O. B.: Incorporation of mineralogical composition into models of the radiative properties of mineral aerosol from UV to IR wavelengths, J. Geophys. Res., 104(D8), 94239444, 1999.

Tanre, D., Kaufman, Y. J., Holben, B. N., Chatenet, B., Karnieli, A., Lavenu, F., Blarel, L., Dubovik, O., Remer, L. A., and Smirnov, A.: Climatology of dust aerosol size distribution and optical properties derived from remotely sensed data in the solar spectrum, J. Geophys. Res., 106, 18205-18217, 2001.
Todd, M. C., Karam, D. B., Cavazos, C., Bouet, C., Heinold, B., Baldasano, J.M., Cautenet, G., Koren, I., Perez, C., Solmon, F., Tegen, I., Tulet, P., Washington, R., and Zakey, A.: Quantifying uncertainty in estimates of mineral dust flux: an inter-comparison of model performance over the Bodélé Depression, Northern Chad, J. Geophys. Res., 113, D24107, doi:10.1029/2008JD010476, 2008.

Tsigaridis, K., Krol, M., Dentener, F. J., Balkanski, Y., Lathière, J., Metzger, S., Hauglustaine, D. A., and Kanakidou, M.: Change in global aerosol composition since preindustrial times, Atmos. Chem. Phys., 6, 5143-5162, 2006, http://www.atmos-chem-phys.net/6/5143/2006/.

Vrekoussis, M., Liakakou, E., Kocak, M., Kubilay, N., Oikonomou, K., Sciare, J., and Mihalopoulos, N.: Seasonal variability of optical properties of aerosols in the Eastern Mediterranean, Atmos. Environ., 39, 7083-7094, 2005.

Xin, J., Wang, S., Wang, Y., Yuan, J., Zhang, W., and Sun, Y.: Optical properties and size distribution of dust aerosols over the Tengger Desert in Northern China, Atmos. Environ., 39, 5971-5978, 2005.

Yin, D., Nickovic, S., Barbaris, B., Chandy, B., and Sprigg, W. A.: Modeling wind blown desert dust in the southwestern United States for public health warning: A case study, Atmos. Environ., 39(33), 6243-6254, 2005. 